\title{
The Current Situation of Double Standards on Domestic Violence of Heterosexual Partners
}

\author{
Yirou Jiang* \\ Guangdong Experimental High School, Guangzhou, Guangdong 510000, China \\ *Corresponding author. Email: gabrielle01277@gmail.com
}

\begin{abstract}
For most of the male victims of domestic violence, the public's double standard and unequal support make most of them dare not speak or are not aware of the harm they have suffered. This includes two reasons: the stereotype formed by historical evolution and the pressure imposed by contemporary social media. This paper will elaborate and quantify the current situation of this double standard through experiment. The researchers used a group of between- subject designs and found the same amounts of men and women (1000 in total, 500 respectively). In the experiment, (4 conditions) both sexes watched two videos: male violence against women and female violence against men. After watching, participants scored the inner anger index (1-5 points) as quantitative data to provide calculation materials for the final t-test. The last expectation of the experiment: both sexes generally overreact to female victims of domestic violence but hold most indifference to male victims.
\end{abstract}

Keywords: Sexual Double Standards, Domestic Violence, Current Situation, Heterosexual Partners, Intimate Partner Violence (IPV)

\section{INTRODUCTION}

Thanks to a wave of feminist movements around the world in recent years, a large amount of women, including victims of domestic violence, who were hidden and hurt in previous vicious incidents, have had many opportunities to speak out and fight for equality. The main function of social media is to drive the mainstream view of the report into the heart, so that most people now hear the word "domestic violence" and immediately feel an implicit sympathy for women. As a matter of fact, all this thinking comes from data that defends feminism. The reason these figures are biased is that they contain only self-reports of female victims [1] and official reports of crime in some parts of the judiciary. [2] According to the Comprehensive Domestic Violence Statistics for Northern Ireland police, which only recently began, the number of male victims of intimate partners is at an all-time climax. Thus, the public perception of gender labelling in domestic violence stems partly from the statistical neglect and lack of reporting of official data. [3]

To dig deep into the feminist perspective, the evolutionary footprint of human history is being traced. Especially after the transition from matriarchal society to patriarchal society, it became part of human instinct to maintain the role expectation of both sexes. In other words, over thousands of years, genes have continued to evolve not only physically but also mentally and mentally. As a result, stereotypes about gender differences were born. The original intention of feminists is also to try to escape from a psychological oppression and bondage by instinct and environment for a long time. However, the fact that men are also dulled and unaware by an unchangeable "masculinity" label is also a psychological trigger for male victims of domestic violence. Many male victims are ashamed of being beaten by a "weak" woman, so in most cases they prefer to be more tolerant and refuse to speak out. For those brave enough to speak up, the gender stereotypes and insults society imposes on them lead to a second barrier to male victims being unveiled. The difficulties of both sides can be reflected in other data: the proportion of depression in male college students is much higher than that in female college students. [4]

Another possible factor about the existence of double standards of domestic violence (which is also believed by most people) is that the proportion of male violence is much larger than that of female violence in all intimate partnerships. Therefore, we must put forward a question that needs to be answered relatively 
objectively: in all intimate partner violence, are there more female perpetrators? Or are there more male perpetrators? Or is the amount of batters of both sexes equivalent in general society?

At this stage, the double standards of domestic violence to be solved does not only exist in the public opinion guidance or the degree of inequality attack, but also in the relevant response measures and legal provisions of the government, just like the medical inequality in racial double standards in many countries. Therefore, the conclusion of this work is that if the statistics indicate that the number of male and female perpetrators of intimate partner violence is almost the same, then most judicial systems have great prejudice and inequality in the adjudication of domestic violence. [5]

\section{PRESENT WORK}

To study the double standards in domestic violence, the experimental research in this paper is different from previous research in that it focuses on documenting the current situation. The specific situation includes the different views of men and women on domestic violence, and the changes in the degree of views or emotions held by men and women when they are victims respectively, in which show the severity of the current dual indicators of domestic violence.

\subsection{Experiment 1}

\subsubsection{Method}

Researchers reported all measures, manipulations, and exclusions. This study was approved by and carried out in accordance with the recommendations of the Institutional Review Board for human participants with written informed consent obtained from all participants.

\subsubsection{Participants}

Because before this article, the relevant research literature on the double standard phenomenon of heterosexual intimate partner violence was very rare. Therefore, when designing this experimental study, the researchers chose not to consider the age group or income level of the participants as part of the independent variable. Therefore, the design choices for the experimental participants are as follows: 1060 participants, 530 men and 530 women respectively. After all the experimental measurements, the researchers excluded 60 sample data according to some unreliable data (including too long answering time, questionnaire answers do not meet the experimental regulations, etc.). Therefore, the final reliable experimental participants were 1000, 500 men and 500 women.

Because the hypothesis of this study involves the investigation of two groups of relative phenomena, the comparative analysis of the final experimental data is indispensable. According to this experimental direction, the researchers finally collected the experimental data of each group and calculated the average in each case with t-test as quantification. Using a paired t-test at a 5\% alpha level (two tailed) threshold with $80 \%$ statistical power.

\subsubsection{Experimental design}

This paper describes the current situation of double standard on domestic violence on heterosexual partners. The researchers designed two experiments as a reference.

The first experiment is between-subject design. The number of participants is 1000: 500 men and 500 women. The experiment is divided into two sets. The participants in the first set are 500 men. First, everyone needs to watch two videos: a video of a man beating a woman and a video of a woman beating a man. In the video, men and women have the same degree of violence and results. After watching the video, 500 participants immediately conduct a scoring survey. They make a reaction index evaluation on their emotions after watching the two videos respectively, so as to quantify the degree of double standard on domestic violence from the perspective of males. In this experiment, the researcher used "anger" to represent post-viewing emotion, and participants had to choose an answer from 1-5 points. (see Figure 1) 

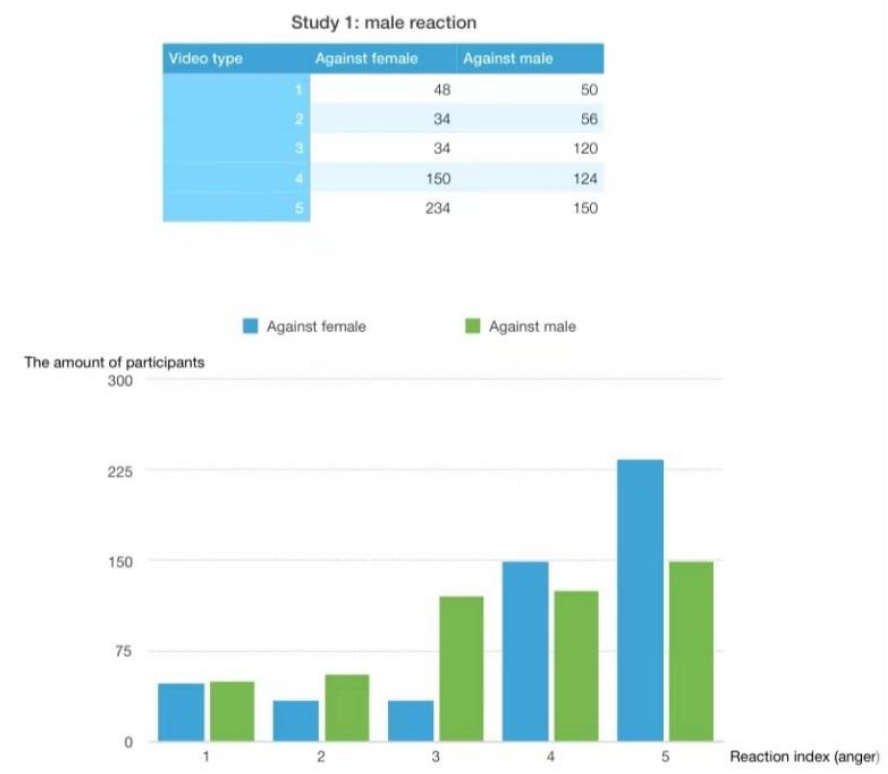

Figure 1 Male Reaction

Figure 1. Referring to set 1 of the first experiment, this bar graph explains the current situation and attitude of domestic violence double standard from the perspective of male participants. The $y$-axis stands for the amount of participants, and the $\mathrm{x}$-axis stands for the anger reaction index (1-5).

The participants in the second set are 500 women. The following experimental process is the same as the first set: first, two videos are played in front of everyone: a video of physical conflict between a man beating a woman and a woman beating a man, and the degree and results of violence between men and women in the video are the same. After watching the video, 500 participants immediately conduct a scoring survey. They make a reaction index evaluation on their emotions after watching the two videos respectively, so as to quantify the degree of double standard on domestic violence from the perspective of females. In this experiment, the researcher used "anger" to represent post-viewing emotion, and participants had to choose an answer from 1-5 points. (see Figure 2)
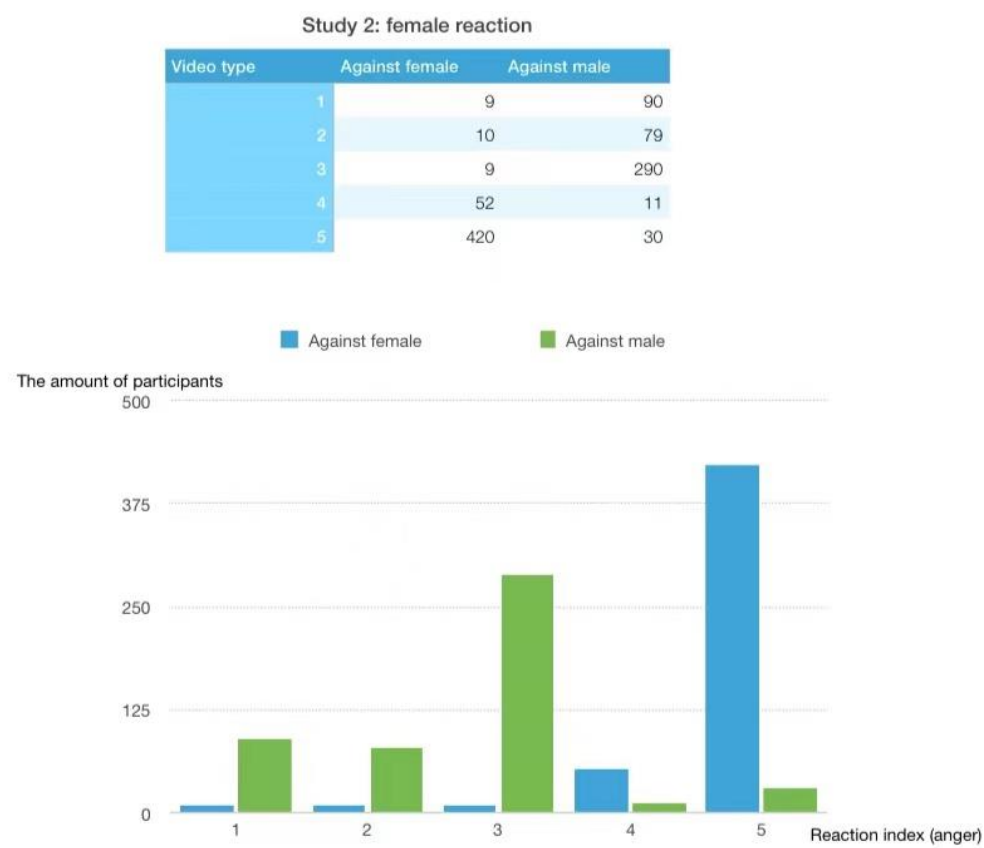

Figure 2 Female Reaction 
Figure 2. Referring to set 2 of the first experiment, this bar graph explains the current situation and attitude of domestic violence double standard from the perspective of female participants. The $y$-axis stands for the amount of participants, and the $\mathrm{x}$-axis stands for the anger reaction index (1-5).

Independent variable is video type (male vs female / female vs male)

Dependent variable is anger reaction index (1-5)

H1: there is prejudice and indifference to the male victims of female to male violence. (underreaction)

$\mathrm{H} 2$ : people are more sympathetic to the female victims of male to female violence (overreaction)

\subsubsection{Procedures}

Two kinds of physical conflict videos were played in front of all participants (men beat women and women beat men), and then all people filled the questionnaire of anger reaction index, scoring from 1-5 points.

\subsubsection{Measure 1}

Description of experimental materials: Video: before researchers record the video to be used, two actors were chosen (a man and a woman), and their height $(1.75 \mathrm{~m})$ and weight $(63 \mathrm{~kg})$ should be the same. During the recording, the two actors hit each other with the same force. The boxing dynamometer were used to ensure that two people have the same level of violence, such as 300 pounds. Most importantly, the video clearly showed that the violent consequences of the two videos (that is, two people beat each other) were the same, that is, if one person was broken and the other was killed, this phenomenon would cause direct bias and error to the participants.

\subsubsection{Data Analytic Approach}

Using a paired t-test at a 5\% alpha level (two tailed) threshold with $80 \%$ statistical power and calculating the reaction mean in every set.

\subsection{Experiment 2}

\subsubsection{Method}

Researchers report all measures, manipulations, and exclusions. This study was approved by and carried out in accordance with the recommendations of the Institutional Review Board for human participants with written informed consent obtained from all participants.

\subsubsection{Participants}

1000 participants in Experiment 1 (500 females and 500 males)

\subsubsection{Experimental Design}

The self-report measure is being used in the second experiment. That is, the questionnaire needs to be filled by 1000 participants after scoring the first experiment. The purpose of this experiment is to make a reference to the average data results of the first experiment, so as to study whether there is correlation and the reliability of the experiment. Finally, make a paper review without recording statistical calculations.

The researcher will make a 20-question questionnaire based on a scene of male and female violence, and then ask the participants to put forward their views.

\subsubsection{Measurement}

Each question in the questionnaire has five options. The common measurement method Likert Scale of selfreport measure is being used: Strongly Disagree, Disagree, Neutral, Agree, Strongly Agree

\section{CONCLUSION}

The list as follows:

1. Serious double standard on domestic violence of heterosexual partners.

2. Most people pay special attention to male victims and cannot treat male and female sexual victims equally, although under specific circumstances, the degree and consequences of men beating women and women beating men are the same.

Generally, the phenomenon of the double standard of domestic violence in heterosexual intimate partnership is more serious, which is mainly reflected in that under the influence of stereotype, most people pay special attention to male victims and cannot treat male and female sexual victims equally, although under specific circumstances, the degree and consequences of men beating women and women beating men are the same.

This double standard also makes a connection with the conclusions of many previous literature, and women will report their injuries more actively.

The limitation of the first experiment is that the topic of domestic violence has not been further expanded, and factors such as participants' family background, education level and income have not been taken into account. Another disadvantage is that in some specific cases, the double standard attitude 
response is only judged by the index of emotion, which is an incomplete quantitative method. In addition, the answering time of participants after watching the video was not considered, which was also a confound factor in the experiment. In the second experiment, the questionnaire often has too many subjective factors and social desirability effect.

\section{REFERENCES}

[1] Mooney, J. (1994). The hidden figure: Domestic violence in north London. https://islingtoncrimesurvey.files.wordpress.com/2 016/02/domestic-violence-north-london1.pdf

[2] Claes, J.A., \& Rosenthal, D.M. (1990). Men who batter: A study in power. https://www.ojp.gov/ncjrs/virtuallibrary/abstracts/men-who-batter-women-studypower

[3] Archer, J. (2000). Sex differences in aggression between heterosexual partners: A meta-analytic review. https://psycnet.apa.org/record/2000-15524001

[4] Paola Pedrelli, Ph.D., a, Brian Borsari, Ph.D., b,c Sarah Ketchen Lipson, Ed.M.,d.e. Justin E. Heinze, Ph.D.,f and Daniel Eisenberg, Ph.D.e,g. (2016). Gender Differences in the Relationships Among Major Depressive Disorder, Heavy Alcohol Use, and Mental Health Treatment Engagement Among College Students. https://www.ncbi.nlm.nih.gov/pmc/articles/PMC49 87072/

[5] Dobash, Russell P.; Dobash, R. Emerson (2004). "Women's Violence to Men in Intimate Relationships: Working on a Puzzle". http://www.brown.uk.com/domesticviolence/dobas h.pdf 